\title{
Interactive comment on "Comment on "Estimating the depth and evolution of intrusions at resurgent calderas: Los Humeros (Mexico)"' by Urbani et al. (2020)" by Gianluca Norini and Gianluca Groppelli
}

\section{Luca Ferrari}

luca@unam.mx

Received and published: 13 October 2020

As I expressed in my previous review, I consider that Norini and Groppelli provided solid geological information that question the model presented in Urbani et al. (2020), although the first version at places could have been a bit overtone. In this new version the authors smoothed the parts that may have been considered unappropriated for a scientific debate and provide more details that confirm their in-depth knowledge of the field geology and tectonics of the Los Humeros caldera. Their comment is well written and illustrated. It is also properly organized with precise explanation on four issues that 
relative age of faulting and include new material. Here Norini and Groppelli provide a wealth of field data, now also in table format, and a new, remote sensing-based thermal anomaly map, which does not support the Urbani et al. model. The other three sections are essentially the same as the previous version and show how topographic data, geothermal well log data, and volcanic stratigraphy supported by isotopic ages are also at odds with the Urbani et al. model. I think that the comment has solid scientific bases and the questioning is now expressed in a polite form so that it can be accepted for publication as is.

Interactive comment on Solid Earth Discuss., https://doi.org/10.5194/se-2020-168, 2020. 